\title{
ECOLOGICAL DESIGN OF A CRAYFISHING PROGRAM TO CONTROL POPULATION DENSITY OF THE INVASIVE SPECIES PROCAMBARUS CLARKII IN DOÑANA NATIONAL PARK FRESHWATER MARSH (SPAIN)
}

\author{
GUTIÉRREZ-YURRITA, P. J. ${ }^{1 *}$-MARIN-GARCIA, L. ${ }^{1}-$ MONTES, C. ${ }^{2}$ \\ ${ }^{1}$ Interdisciplinary Centre for Research and Studies on Environment and Development, National \\ Polytechnic Institute \\ C/30 de Junio de 1520 S/N, Col. La Laguna Ticomán. México D.F., 07340. \\ (phone: $+52-55-5729-6000$ ext. 52708; fax: $+52-55-5729-6000$ ext. 52710) \\ ${ }^{2}$ Department of Ecology, University Autonomous of Madrid (Spain) \\ *Corresponding author \\ e-mail:pgutierrezy@ipn.mx
}

(Received $16^{\text {th }}$ Sept 2014; accepted $1^{\text {st }}$ Dec 2014; corrected online $23^{\text {rd }}$ May 2016)

\begin{abstract}
The exploitation of Procambarus clarkii in Doñana National Park's freshwater marsh (DNP) has been economically important to the local human population since the 1970s. The high density of this crayfish species has been causing a major environmental impact in the Park by the substantial reduction of submerging aquatic macrophytes prairies due to its broad trophic spectrum and feeding habits, which turned the environmental frame (consisting in clear water equilibrium) into a turbid water balance. Differences in population dynamics of three population groups of $P$. clarkii in the DNP freshwater marsh were compared and analyzed from a fishery perspective. The objective is to reduce their ecological impact using optimal crayfishing management. Maximum growth curves showed that crayfish have different growth optimums. Recruitment of young crayfish varies between different populations; when there is an excessive increase in the density of juveniles in a population and conditions are stressful, their growth is deficient. If these conditions persist, the population could become stunted. Fishery for commercial gain is banned in DNP; however, a model of fisheries program aimed at controlling the excess population of crayfish can be effective in halting the ecological impact of this invasive species while providing an opportunity for poachers to have viable productive options. The model proposed can help to solve the problem of crayfish "poaching" through the legalization and strict control of harvesting practices.
\end{abstract}

Keywords: population control, non-native crayfish, ecological impact, natural protected areas.

\section{Introduction}

Procambarus clarkii (Girard) is a crayfish species native to the Louisiana swamps (USA) that was introduced and released into Guadalquivir marshes in 1974, causing the species subsequent establishment and spread throughout the marshlands area (GutiérrezYurrita et al., 1999). Red swamp crayfish has played a key role in the functioning of aquatic ecosystems after its introduction (Gutiérrez-Yurrita and Montes, 1998; Geiger et al., 2005; Matsuzaki et al., 2009); its direct impact produced thereafter on the ecosystem should be considered from three perspectives. The first is its potential for altering the total production of the ecosystems (Momot and Romaire, 1983; Gutiérrez-Yurrita et al., 1999; Gutiérrez-Yurrita, 2004; Geiger et al., 2005). The second relates to its feeding habits. As a major consumer, $P$. clarkii may perform a significant role ingesting large quantities of detrital organic material (Ilhéu and Bernardo, 1995; Gutiérrez-Yurrita et al., 1998; Correia et al., 2005) and, to a lesser extent; it consumes great quantities of 
insects (Gutiérrez-Yurrita and Montes, 2004; Crehuet et al., 2007). In addition, some authors have suggested that $P$. clarkii is responsible for the disappearance of two species of mollusk (Lymnaea peregra Müller (1774) and Lymnaea stagnalis Linnaeus (1758)), and possibly, for the local extinction of at least three species of macrophytes (Myriophyllum alterniflorum DC, Utricularia australis R. Br., and Ceratophyllum demersum L). This may be due to the impact from consumption of mollusks and macrophytes by crayfish, or it may be an indirect effect due to the shredding and uprooting of macrophytes by crayfish and consequent loss of food and refuges for the mollusks (Montes et al., 1993; Gutiérrez-Yurrita, 1997). This consumption, and the breaking of macrophyte stems and branches, promote the acceleration of the decomposition process, transforming the coarse particulate organic matter into fine particulate organic matter, thus providing food for collector-gathering groups and stimulating primary production by the increase of nutrient turnover rates (Ilhéu and Bernardo, 1995). If the availability of vegetal detritus is low, then crayfish trophic behavior shifts to macrophyte grazing (Gutiérrez-Yurrita et al., 1998; Gutiérrez-Yurrita, 2004; Correia et al., 2005). At high crayfish densities, foraging may be so extensive as to completely modify the habitat, destroying the algal beds and submersed macrophyte prairies (Gutiérrez-Yurrita et al., 1998; Ilhéu et al., 2007). The third and final perspective that must be considered is the role of crayfish as prey of native and introduced fishes (black bass), terrestrial vertebrates (Iberian lynx) and birds (imperial eagle) (Elvira, 1998; Montesinos et al., 2008).

Moreover, red swamp crayfish is demonstrably an ecosystem engineer species, physically transforming its environment and altering the availability of resources for other species (Gutiérrez-Yurrita and Montes, 1998; Matsuzaky et al., 2009). These changes have been principally achieved by structural modification of burrowing, which disturbs the substrate and increases turbidity, affecting the growth of macrophytes. The most important ecological consequence of the reduction in aquatic vegetation cover is the enriching of the water column with nutrients, which favors the development of phytoplankton communities, changing the ecological balance from fresh to turbid water (Scheffer et al., 1993; Bravo et al., 1994; Ackefors, 2000; Rodríguez et al., 2005).

Finally, it has to be borne in mind that due to this species worldwide importance as a culinary ingredient in human diet (Ackefors, 2000; Romaire et al., 2005; McClain et al., 2007), red swamp crayfish fishing in Guadalquivir marshes is the most valuable crayfish fishery in Europe with approximately 3,000ton/yr., but it also brings with it an impact on the ecosystems due to its exploitation (Asensio, 1991; Gutiérrez-Yurrita et al., 1999; recently Seafood, 2005; Martín-López et al., 2011). Fishermen cause severe damage to riparian vegetation when setting traps, resulting in a high mortality rate of aquatic vertebrates (fish, amphibians and reptiles) and birds. In the 1989 season, more than 42,000 birds and more than 750,000 aquatic vertebrates of various species died in traps set in the DNP and the Brazo del Este Natural Park (Gutiérrez-Yurrita et al., 1997). Two of these bird species (Marmaronetta angustirostris and Porzana puzilla) are featured in the Red Book of Endangered Species of Spain (Gutiérrez-Yurrita et al., 1997). The presence of the red swamp crayfish in the marshlands of the Lower Guadalquivir also damages the rice fields due to its burrowing and grazing behavior (Anastácio et al., 2005).

Once a successful introduction has been accomplished, it is desirable that no further insertions take place (Gutiérrez-Yurrita and Montes, 1999a; Gutiérrez-Yurrita, 2004; Martín-López et al., 2011; Elio-Siesa et al., 2012). Decision-makers are invited and 
strongly encouraged to promote measures to minimize the impacts and allow wise utilization of the new resource, or to highlight ecosystem services to improve conservation practices, thus minimizing impacts caused by the newly introduced species (Gutiérrez-Yurrita, 2005; 2011; Marchi et al., 2011; Martín-López et al., 2011; MacedaVeiga et al., 2012; Homans and Smith, 2013).

At the time this research was conducted, resource managers are faced with the problems of conserving natural protected areas and utilizing crayfish stocks for commercial purposes; the results of this research have been focused in developing a crayfish population model that can be quick and effectively applied to ensure a holistic management of DNP freshwater marsh (Gutiérrez-Yurrita, 2009, 2014; Maceda-Veiga et al., 2012; Marchi et al., 2012). A holistic approach to the management of crayfish in Doñana would be favorable since it allows the evaluation of a comprehensive policy management which would include a more ample focus considering the social, economic and administrative sectors of the park (Gutiérrez-Yurrita et al., 2014).

\section{Materials and Methods}

\section{The study area}

Currently, the red swamp crayfish occupies the entire Guadalquivir freshwater marsh, streams and nearby rivers. However, this study focuses on stocks located in the DNP freshwater marsh because this is a very important protected area in Europe. DNP is located in the mouth of the Guadalquivir River (Fig. 1). From a geomorphologic point of view, the DNP includes 3 eco-districts: aeolian (dunes), coastal, and marsh. The marshland of the Park covers an area of 27,000 ha of mixed fluvial-marine origin with a clay substrate where the crayfish populations have proliferated, causing major changes in food web structure (Gutiérrez-Yurrita et al., 1996). The DNP freshwater marsh is characterized by its hydrological cycle. The yearly flooding period followed by desiccation of the marsh is not influenced by the tides. The marsh usually floods from October to March, with a period of water retention of approximately 3 months (AprilJune). The water levels decreases progressively from May to June when the marsh dries out completely (Bravo et al., 1994; Gutiérrez-Yurrita and Montes, 1999a). The dominant aquatic vegetation in DNP's temporary freshwater marsh comprises Typha domingensis, Juncus effusus, Scirpus maritimus and Eleocharis palustris close to the riverbank. The macrophyte community is dominated by Ranunculus peltatus and some clumps of Zannichellia obtusifolia, Potamogeton tricoides, Potamogeton pectinatum and Callitriche truncata and by the algae Chara connivens (Ilhéu and Bernardo, 1995; Gutiérrez-Yurrita et al., 1998). A more complete description of the study area can be found in Gutiérrez-Yurrita (1997). It is worth noticing that this study was begun and completed during one of the lowest precipitation cycles the region has experienced in many decades (rain deficit was $>240 \mathrm{~mm}$ per year).

\section{Crayfish sampling}

Crayfish were trapped with unbaited funnel traps of two types following the method described in Gutiérrez-Yurrita et al. (1997). Due to the highly nocturnal activity of these individuals, there is no need to bait traps. The traps were left in operation for 72 consecutive hours every week, but were checked on every morning, especially to free other animal species that might have been erroneously trapped, such as turtles. After the 
supervision of the traps, these were immediately placed back into place to complete their 72 hour operation cycle. It is important to mention that, no animals were harmed due to the traps designed and set for the purpose of this research. Monthly samples of crayfish were taken from January to April in over three consecutive years at three different sites in the sandy zone adjacent to the natural temporary freshwater marsh: 1) Stream Guayules; 2) Stream Soto Grande; 3) Stream Soto Chico (Fig. 1), where crayfish abundance is highest (Gutiérrez-Yurrita, 1997). Sampled animals were measured (considering total and carapace length; wet and dry weight) and sexed. Their degree of sexual maturity (FI: mature; FII: immature) was estimated by dissection and histological analysis of the gonads (Carmona et al., 2004). Crayfish become cannibals if they are found in high densities and have no other source of food. When these animals are inside a trap for too long, the two variables are combined and the crayfish start fighting each other. In these fights, the one with the smallest size always loses, or they reach some sort of draw, but both lost chelae and locomotors appendages. In order to minimize the ecological impact of trapping and to avoid crayfish cannibalism, the sampling time was of $24 \mathrm{~h}$ (Gutiérrez-Yurrita et al., 1997). To understand the dynamics of the of crayfish population in the temporary freshwater marsh of Doñana, their life cycle must be considered. Gutiérrez-Yurrita (1997) found that female gonadal development has 5 stages from state 0 (at rest) to stage IV (degeneration). Gonadal maturity begins in November (phase 1) and ends in April (phase IV). The most active months for reproduction are January and February. The months of March and April are for recruiting. The hydroperiod is essential for the reproductive period of the crayfish to extend or shorten it a couple of months.

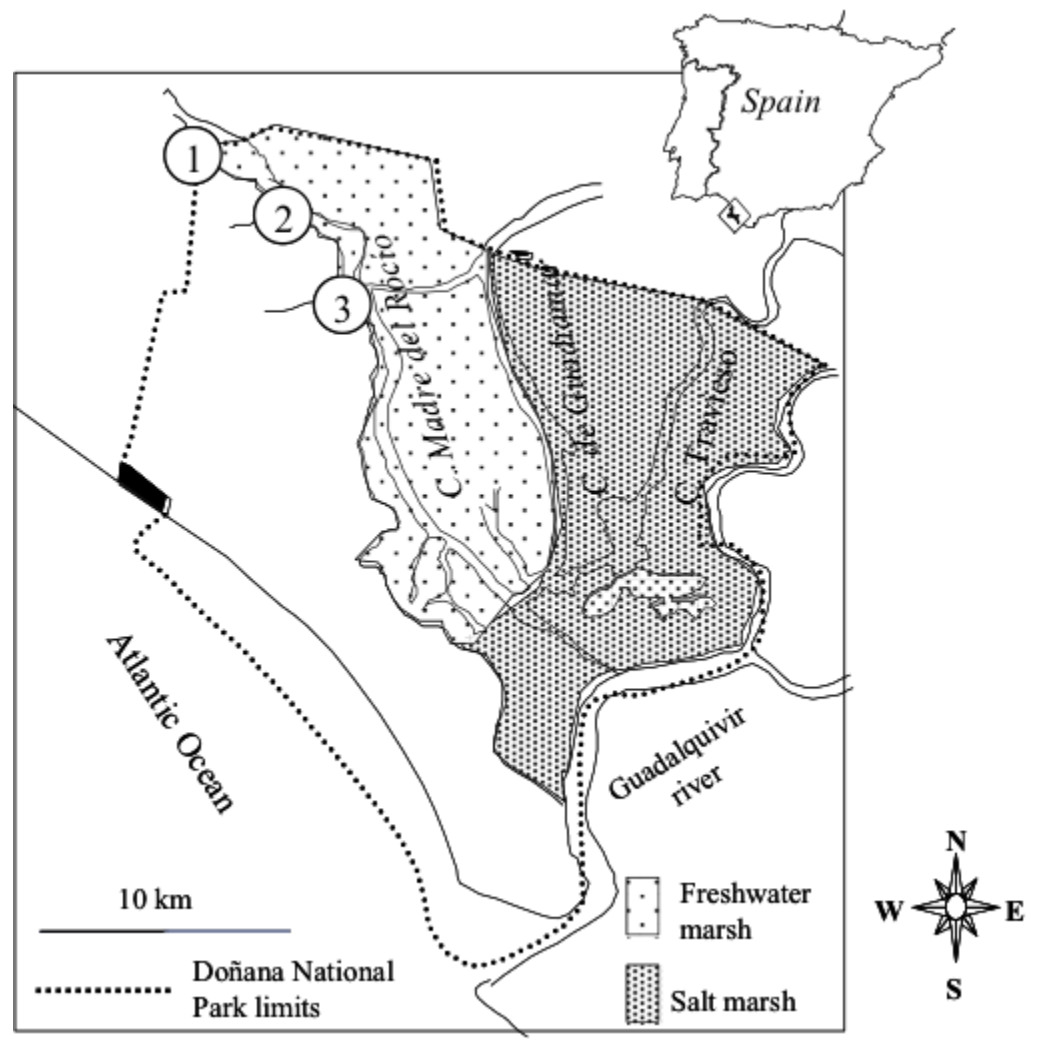

Figure 1. Location of Doñana National Park. Sampling sites: 1) Stream Guayules. 2) Stream Soto Chico. 3) Stream Soto Grande. 


\section{Data analysis}

Morphometrics (wet weight vs. carapace length) (w vs. CL) were estimated using a multiplicative model fitted by taking logarithmic transformations and applying least squares linear regression analysis, $\mathrm{w}=\mathrm{a}\left(\mathrm{CL}^{\mathrm{b}}\right)$ (Ott, 1993). Slopes resulting from calculated relations between species and season were compared using a statistical technique described by Ott (1993) with $\mathrm{p}=0.05$. Sample data of carapace length of crayfish were collected in each ecosystem on each season and grouped in $0.2 \mathrm{~cm}$ size increments according to Gutiérrez-Yurrita (1997). An initial estimate of the number of recruitment classes presented, and mean carapace length variance and proportion of crayfish in each recruitment class were obtained through a graphical separation technique by using the probability paper method (Pauly and Morgan, 1987). Growth rates of crayfish recruitment classes were estimated from seasonal von Bertalanffy growth curves modified for invertebrate animal due to their non-continuous growth (moult and intermoult phases) (Pitcher and Hart, 1982; Gutiérrez-Yurrita and Montes, 1999b). Cloern and Nichols (1978) stated that the incorporation of a time-varying coefficient significantly improves the capability of the Bertalanffy model, so we developed the next equation:

$$
L t=\mathrm{L} \infty\left(1-\mathrm{e}^{-\mathrm{K}\left(\mathrm{t}^{\prime}-\mathrm{to}\right)+\mathrm{K} / \mathrm{Q}\left\{\operatorname{sen} \mathrm{Q}\left(\mathrm{t}^{\prime}-\mathrm{ts}\right)-\operatorname{sen} \mathrm{Q}(\mathrm{to}-\mathrm{ts})\right\}}\right)
$$

Here, $L t$ denotes the carapace length of the organism at any given time $t ; L \infty$ is the asymptotic maximum length of the animal; to is a consequence of the mathematical structure the equation, and its presence is, in biological terms, the nominal age at which the length of the animal is zero (Bertalanffy, 1934) under the assumption that the von Bertalanffy growth model describes growth accurately right down to zero length and avoiding bias of this tendency to zero taking into account the sample size of individuals measured as Wang and Thomas (1995) recommended; then we have that $K$ is the intrinsic growth rate of the animal; $t s$ defines the start of the convex segment of a sinusoidal oscillation with respect to $t=0 ; Q=2 \pi /(1-\mathrm{NGT}) ; N G T$ is the duration of nongrowth within a year.

In this model is assumed that anabolism and catabolism coefficients of the growth rates were constant throughout the year according to the Bertalanffy's metabolic rule (the metabolism of an organism is proportional to its weight by a $2 / 3$ power). This is likely to be true for this species, since their metabolic rate changes quantitatively but not allometrically throughout the year (Gutiérrez-Yurrita and Montes, 1999b). The method for estimating von Bertalanffy growth parameters of crayfish is based on the ELEFAN method devised by Pauly and Morgan, included in the Length Frequency Distribution Analysis (LFDA ver. 4.01) package.

The instantaneous rate of total mortality $(Z)$ from length frequency samples was computed by the method described by Beverton and Holt (1956):

$$
Z=\mathrm{K}\{(\mathrm{L} \infty-\mathrm{Lbar}) /(\mathrm{Lbar}-\mathrm{Lc})\}
$$

Where $L c$ is the length at which crayfish are first fully recruited (minimum length at first capture); Lbar is the mean length of crayfish longer than $L c$. This method assumes that growth is deterministic, non-seasonal and is described by the von Bertalanffy growth curve. These assumptions are not always found in crayfish populations, since 
there is no stock recruitment relationship unless there are enough observations to describe the slope at the origin (Holden, 1995). Furthermore, the Beverton-Holt method estimates of the total mortality rate can be quite reliable if the assumptions behind the method are met, and if the length at first capture is well estimated. If not, this model can be used in a simple simulation of the effects of fishing on a population (Pöckl, 2002). As it results, the usual stock recruitment relationship may be expressed as a curve with a convex rising slope, and asymptote or as a dome. Thus, another procedure to estimate $Z$ can be obtained from the slope of the upper limb of the length converted catch curve as suggested by Holden et al. (1995):

$$
\begin{gathered}
\Delta_{t i}=-\ln ((\mathrm{L} \infty-\mathrm{Li}) /(\mathrm{L} \infty-\mathrm{Li}+1)) \\
t i=-\ln (1-1 / 2(\mathrm{Li}+\mathrm{Li}+1) / \mathrm{L} \infty) / \mathrm{K}
\end{gathered}
$$

where $\Delta_{t i}$ is the time taken to grow through length class $i$, and $t i$ is the relative age at the middle of the length class $i$. The curve relating $\ln \left(N_{i} / \Delta_{t i}\right)$ to $t i$ is called the length converted catch curve, and the slope of the right hand limb of this catch curve is $-Z$.

Finally, the simulation model incorporated in LFDA called Slice Length Frequency Data (SLFD hereafter) was used to examine the effects of different minimum length at first capture on population dynamics in a $P$. clarkii population from Doñana's temporary fresh water marsh. A SLFD at a given sample timing is built up of crayfish taken by the sampling gear from a number of cohorts. The numbers and the timing of crayfish recruiting to each cohort to age zero is allowed to vary randomly between cohorts, to allow the effect of different annual recruitment strengths to be investigated. Onwards, the growth parameters are assumed to vary randomly between individual crayfish in each cohort, according to specified probability distributions (Pöckl, 2002). Because crayfish in each cohort are subject to a constant natural mortality rate from birth, and to a constant fishing mortality rate once they have reached a length equivalent to the mean length at $50 \%$ the probability of surviving crayfish of a given cohort, being captured in a length frequency sample at a given sampling time is governed by a logistic selectivity curve (Holden et al., 1995). The parameters of this curve are selected randomly for each sampling time from specified probability distributions, allowing the effects of different selectivities at different sampling times (Pitcher and Hart, 1982). Parameters specified for each growth curve except $t_{o}$, were mean $(\square)$ and either a coefficient of variation when sampling from a Normal or Lognormal distribution, or a range when sampling from a Uniform distribution. Selectivity was estimated as follows: $\mathrm{SL}=1 /\left(1+\mathrm{e}^{- \text {Selk }(\mathrm{Lt}-\mathrm{L} 50)}\right)$. The calculations performed in the SLFD are completely described in the LFDA technical appendix, edited by Holden et al. (1995). The data used to construct the SLFD model were taken from our results derived from the Eq. 1 and Eq. 2.

In order to know growth patterns (ratio K/Z), we used Powell's method updated by Wetherall et al. (1987). This method uses a linear regression based on an algebraic relationship between $L \infty, K, Z$ and the mean lengths in the length frequencies. However, unlike the Beverton-Holt method, it does not directly calculate an estimate of $Z$; rather it comes up with a series of estimates of $L \infty$ and the ratio $K / Z$. Because of the negative correlation between estimates of $L \infty$ and $K$, Holden et al. (1995) recommend calculating an individual value of $K$ for each Powell-Wetherall estimate of $L \infty$ before calculating an overall estimate of $Z$. 


\section{Results}

There were statistical differences in sex ratio (males/females) composition between populations $(\mathrm{p}<0.05)$ and within each population in different sampling months $(\mathrm{p}<0.001)$. Table 1 shows sex ratio and percentage of Form I animals in different populations of crayfish at Doñana's temporary freshwater marsh. In all the populations, sex ratios favoring females were found in reproductive period (March-April). Highest overall mean sex ratio was found in the population located in Soto Grande (1.51), whilst the lowest sex ratio was recorded in the population of Los Guayules (0.74). The population of Los Guayules had the greatest percentage of Form I animals (70.2\%), while the lowest percentage was found in Soto Grande population (48.5\%). The reproductive season was characterized by having the lowest monthly proportion of FI individuals, except in Soto Chico, when FI percentage was the highest (90.1\%).

Table 1. Sex ratio (Males/Females) and percentage of Form I sexually mature (FI) animals in different populations of $P$. clarkii in Doñana National Park natural temporary freshwater marsh.

\begin{tabular}{|c|c|c|c|c|c|c|}
\hline \multirow[t]{2}{*}{ Month } & \multicolumn{2}{|c|}{ Stream Guayules } & \multicolumn{2}{|c|}{ Stream Soto Chico } & \multicolumn{2}{|c|}{ Stream Soto Grande } \\
\hline & $\mathbf{M} / \mathbf{F}$ & $\% \mathbf{F I}$ & $\mathbf{M} / \mathbf{F}$ & $\% \mathrm{FI}$ & MF & $\% \mathrm{FI}$ \\
\hline January & 0.09 & 91.7 & 0.56 & 28.0 & 1.00 & 24.0 \\
\hline February & 0.13 & 95.2 & 1.05 & 54.0 & 1.45 & 70.4 \\
\hline March & 1.02 & 34.2 & 1.14 & 90.1 & 1.64 & 39.4 \\
\hline April & 0.55 & 60.0 & --- & --- & 1.69 & 60.0 \\
\hline Mean & 0.74 & 70.2 & 0.80 & 57.3 & 1.51 & 48.5 \\
\hline
\end{tabular}

--- = No data available.

Table 2 shows monthly carapace length vs. wet weight morphometric relationships and monthly absolute growth rate for all the population analyzed. Except for the individuals of the population of Soto Chico in February, animals showed non-isometric growth. Hence almost all populations studied increase their weight more than their length (relation exponent $>3$ ). Although statistically significant differences were found between monthly morphometric relationships within each population $(\mathrm{p}<0.05)$, population data for individual months were pooled for each population, to assess a general condition factor. Soto Chico population showed the best condition factor (exponent 3.73).

Table 2. P. clarkii monthly weight ( $w$ in $g$ ) vs. carapace length (CL in $\mathrm{cm})$ power relationship $\left(w=a\left(C L^{b}\right)\right)$ and monthly absolute growth rate $\left(w_{2}-w_{1} / t_{2}-t_{1}\right)$ in different habitats into the Doñana National Park natural temporary freshwater marsh*.

\begin{tabular}{l|ll|ll|ll}
\hline Month & \multicolumn{2}{|c|}{ Stream Guayules } & \multicolumn{2}{c|}{ Stream Soto Chico } & \multicolumn{2}{c}{ Stream Soto Grande } \\
& Model & growth rate & Model & growth rate & Model & growth rate \\
\hline January & $\mathrm{w}=0.17\left(\mathrm{CL}^{3.2}\right)$ & 2.88 & $\mathrm{w}=0.01\left(\mathrm{CL}^{3.7}\right)^{\mathrm{a}}$ & 2.07 & $\mathrm{w}=0.15\left(\mathrm{CL}^{3.4}\right)$ & 2.79 \\
February & $\mathrm{w}=0.02\left(\mathrm{CL}^{4.0}\right)$ & 1.17 & $\mathrm{w}=0.27\left(\mathrm{CL}^{3.1}\right)^{\mathrm{b}}$ & 1.5 & $\mathrm{w}=0.03\left(\mathrm{CL}^{4.2}\right)^{\mathrm{d}}$ & 0.69 \\
March & $\mathrm{w}=0.18\left(\mathrm{CL}^{3.3}\right)$ & 0.60 & $\mathrm{w}=21.0\left(\mathrm{CL}^{-0.9}\right)^{\mathrm{c}}$ & & $\mathrm{w}=0.12\left(\mathrm{CL}^{3.6}\right)$ & 0.48 \\
April & $\mathrm{w}=0.09\left(\mathrm{CL}^{3.7}\right)$ & & & & $\mathrm{w}=0.16\left(\mathrm{CL}^{3.3}\right)$ & \\
\hline
\end{tabular}
Pooled data (all places throughout the wet season) $\mathrm{w}=0.18\left(\mathrm{CL}^{3.24 \pm 0.27}\right)$

${ }^{*} \mathrm{r}^{2}>95$ in all the cases except in: ${ }^{\mathrm{a}} 72 \% ;{ }^{\mathrm{b}} 81 \% ;{ }^{\mathrm{c}} 90 \% ;{ }^{\mathrm{d}} 76 \%$. 
Absolute growth rates were higher in the recruitment period than in the reproductive period ( $>2 \mathrm{~cm} \mathrm{CL} /$ month and $>1<2 \mathrm{~cm} \mathrm{CL} /$ month, respectively). Lowest rates were recorded when the freshwater marsh was close to the onset of the natural seasonal loss of standing water in the marshes $(<1 \mathrm{~cm} \mathrm{CL/month).} \mathrm{Carapace} \mathrm{length-frequencies} \mathrm{of} P$. clarkii in DNP are shown in Figure 2. Five cohorts were recognized from 0.5 to $6.7 \mathrm{~cm}$ CL for Los Guayules and four cohorts at the other two places. When all the data for all three populations were pooled, the most frequent cohort found in age class 2 (33\%) when data from all the populations were joined. The least recorded age class was the 4th, which was only evident at Los Guayules. Carapace length of gravid females was quite similar among populations, ranged from 3.3 to $4.5 \mathrm{~cm} \mathrm{CL} \mathrm{(Fig.} \mathrm{2).}$

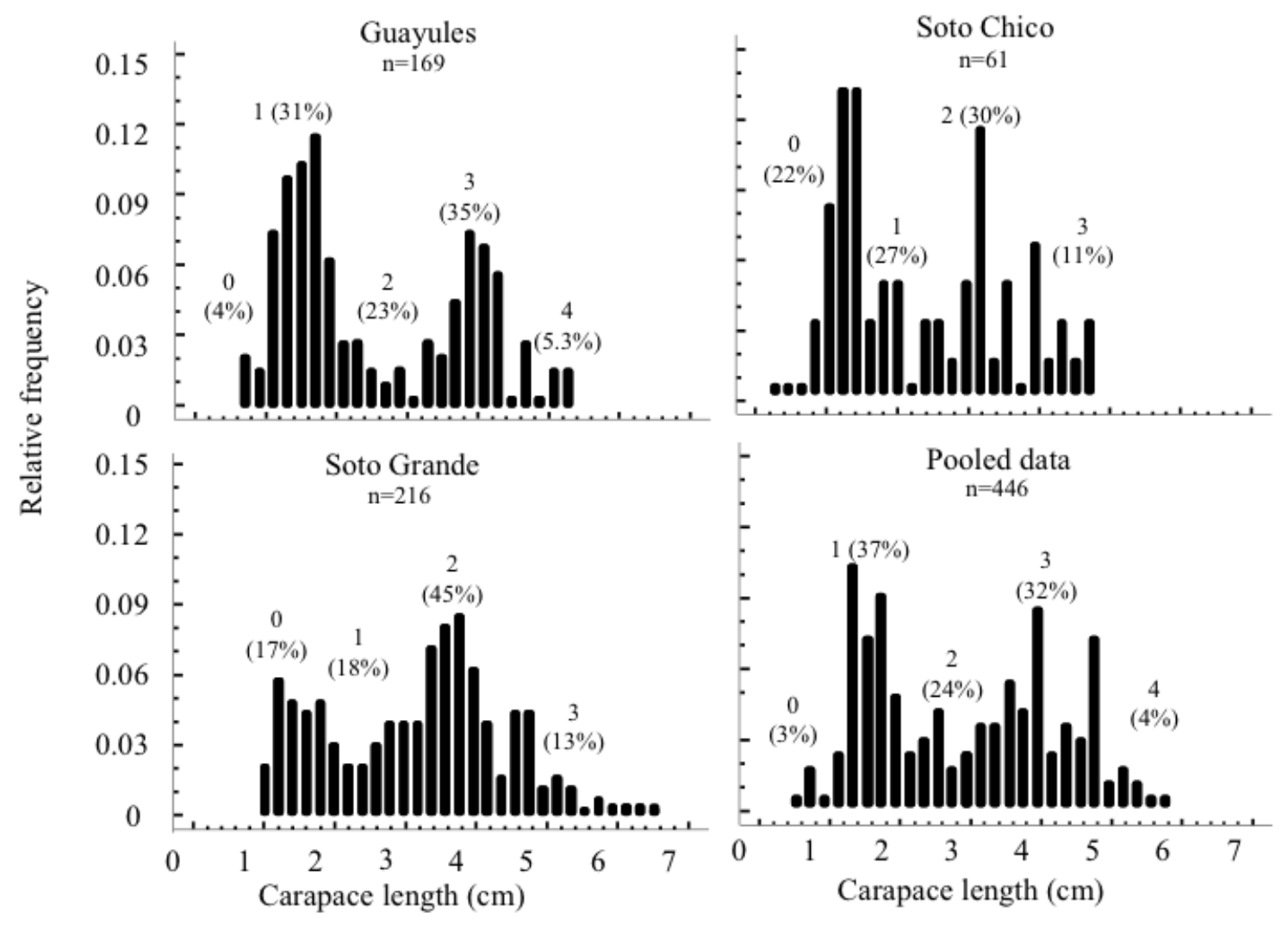

Figure 2. Carapace length-frequencies of P. clarkii in Doñana National Park natural temporary freshwater marsh. Each cohort is indicated by numbers, and the percentage of occurrence of any cohort in the entire population is indicated by numbers in parenthesis). Bars depict the mean carapace length of each reproductive stage (Form I and Form II).

Figure 3 shows the two-dimensional contour plots of $\mathrm{K}$ and $L \infty$ from von Bertalanffy's seasonal growth model for different populations of $P$. clarkii in DNP. Crayfish in Soto Grande grows faster than in the other places, reaching the largest length $(K=0.395 L \infty=7.11)$. However, maximum growth areas of this population showed more amplitude than the maximum growth areas of the other populations (the darker areas in Figure 3 the higher growth parameters scores). On the other hand, although crayfish from Los Guayules had the lowest growth value, crayfish from Soto Chico had the lowest asymptotic length (Los Guayules: $K=0.303 ; L \infty=5.84$; Soto Chico: $K=0.378 ; L \infty=4.68$ ). 


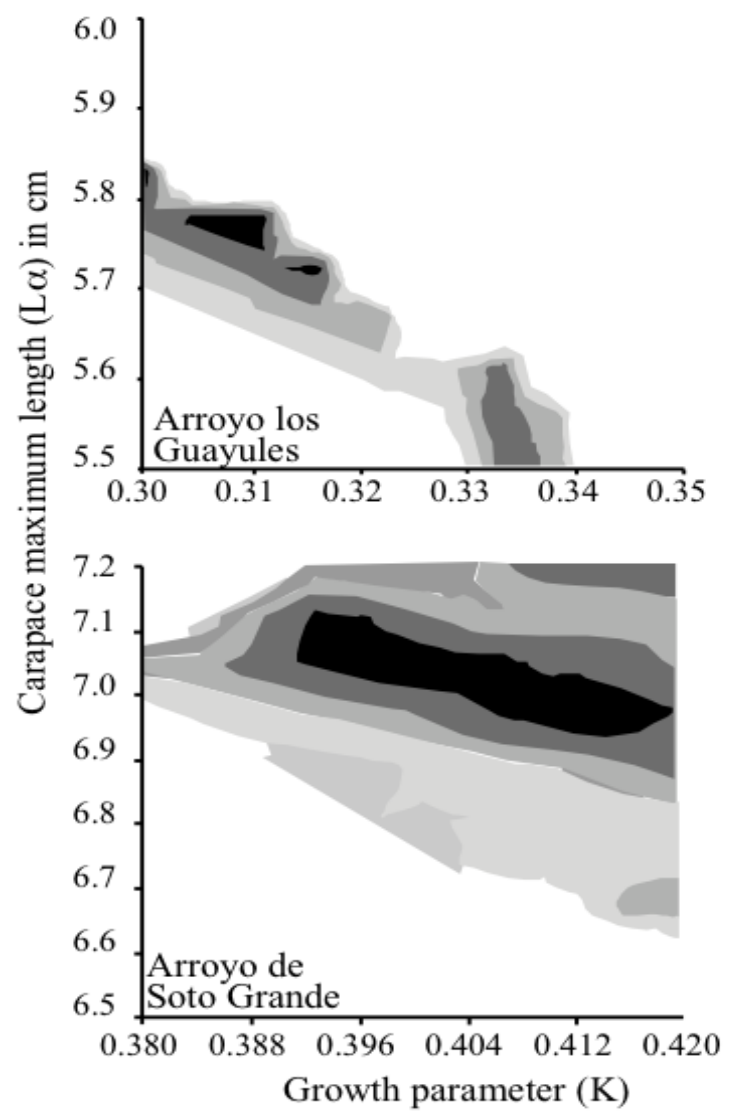

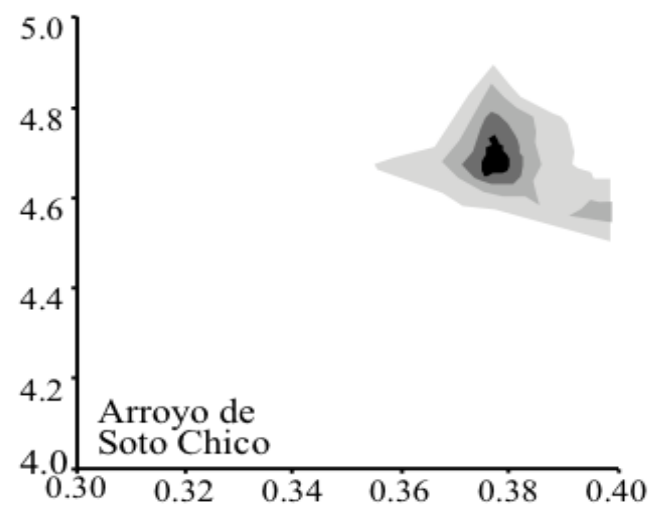

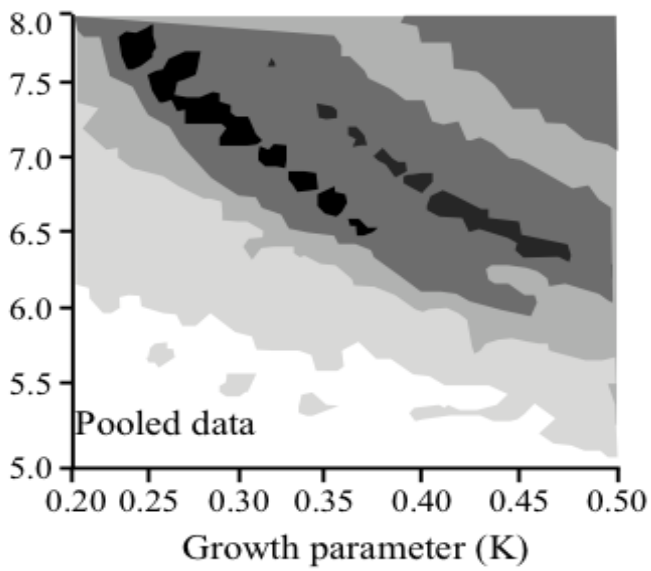

Figure 3. Two dimensional contour plot of $K$ (growth rate) and Lo (asymptotic length) from von Bertalanffy's seasonal growth model for different populations of P. clarkii in Doñana National Park natural temporary freshwater marsh. Light areas represent low values of the score function and the dark areas represent high values. The amplitude of each area shows growth response to the environmental change.

We can also observe in Figure 3 (pooled data) that crayfish in Doñana's freshwater marsh exhibit a very adaptive growth, adjusting it accordingly to the environmental changes (temperature, oxygen levels, water regime) in order to fit the best growth at every time. This is an important issue because the model states the existence of a relationship between growth factors that, when combined, encourage the individual to achieve the larger size of its species in the shortest time possible $(K ; L \infty)$. Therefore, when growth estimates have several populations of the same species, they can be compared with each other and the deviations of these parameters are due to a greater instance of environmental factors.

The overall yearly growth data of each population were joined in one lengthfrequency histogram to compute seasonal von Bertalanffy growth curves of $P$. clarkii in DNP (Fig. 4). By this method 7 cohorts were recorded (from +0 to 6), but cohorts 5 and 6 had practically no animals (occurrence percentage of animals in these class ages was less than the $2 \%$ of the entire population). The overall von Bertalanffy model parameters were $K=0.321 ; L \infty=6.92 ; T o=-0.58$. 


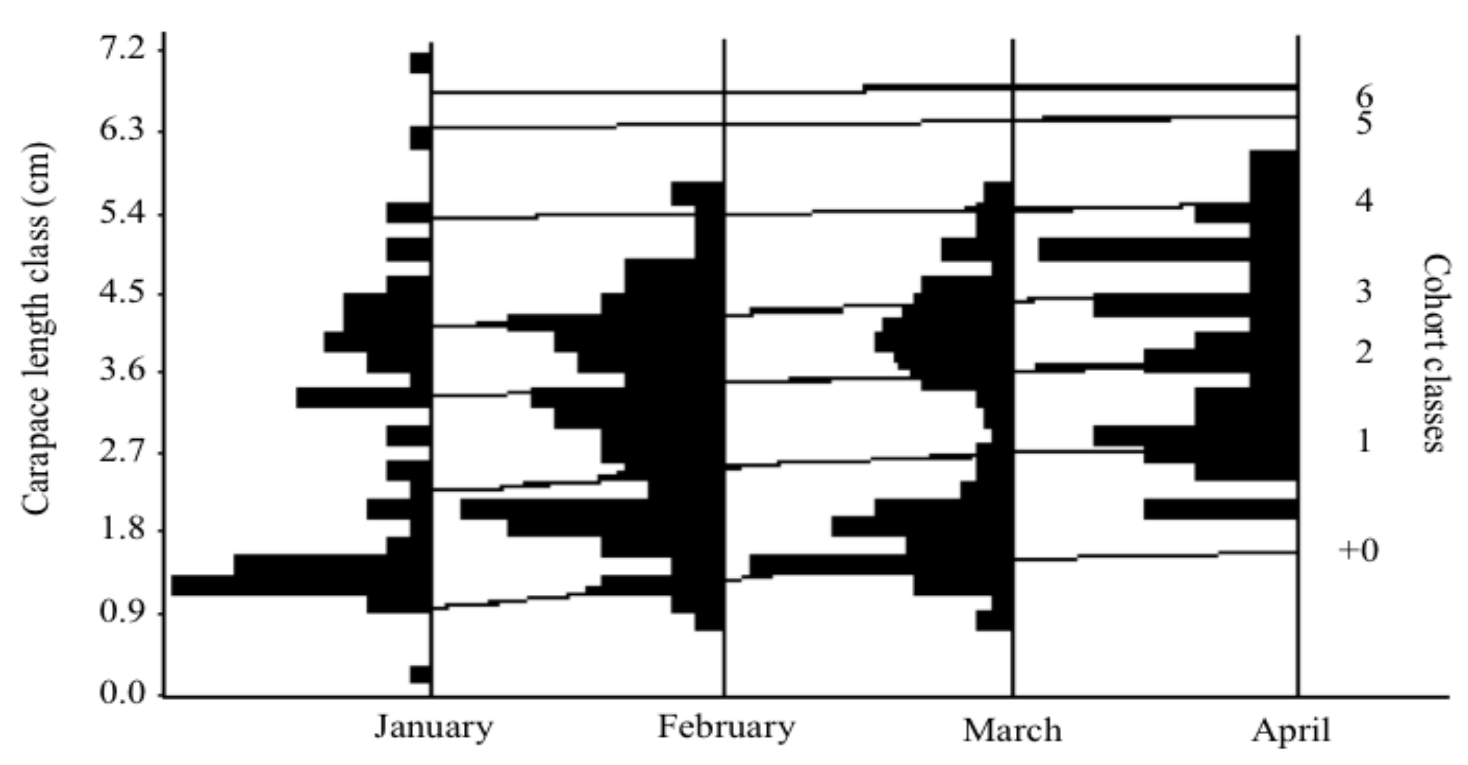

Figure 4. Seasonal growth curves of P. clarkii in Doñana National Park natural temporary freshwater marsh. Each line corresponds to a different cohort class. Length-frequency histograms show size class structure dynamics on crayfish populations.

Seasonal growth curves of $P$. clarkii using simulated dataset are presented in Figure 5. Seven cohorts were recorded, but now the individuals of the cohorts 5 and 6 represent more than $25 \%$ of the entire population. The von Bertalanffy seasonal growth parameters are: $K=0.321 ; L \infty=7.02 ; T o=-0.52 ; T s=-0.56 ; N G T=0.46$.

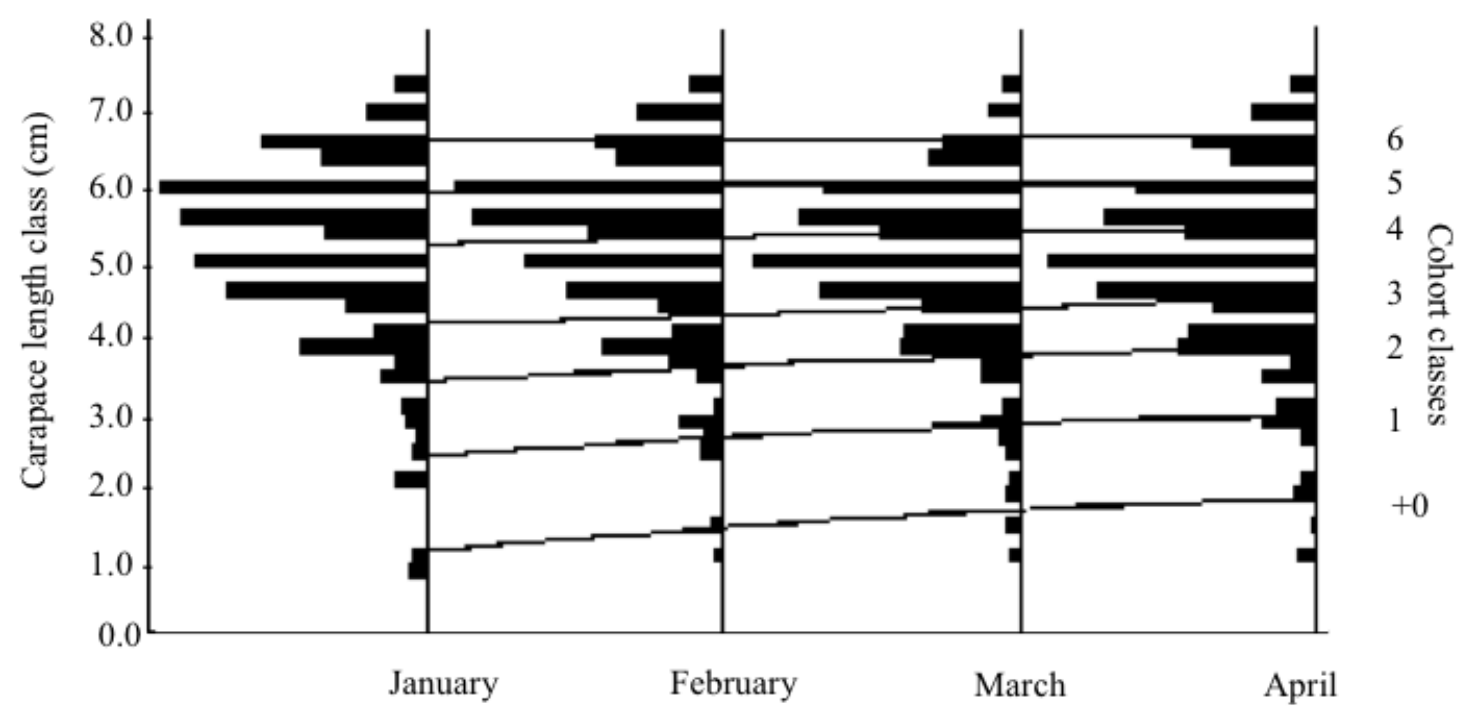

Figure 5. Seasonal growth curves of P. clarkii using simulated dataset. Each line corresponds to a different cohort class. Length-frequency histograms show size class structure dynamics on crayfish populations with simulated dataset. 
The annual period with no growth in size is approximately one month between March and April. In Figure 6 we can observe that optimum scope for growth (greatest $K$ and $L \infty$ fit) when simulated dataset is used; it is very narrow if we compare it with the scope for growth utilizing recorded dataset (Fig. 3).

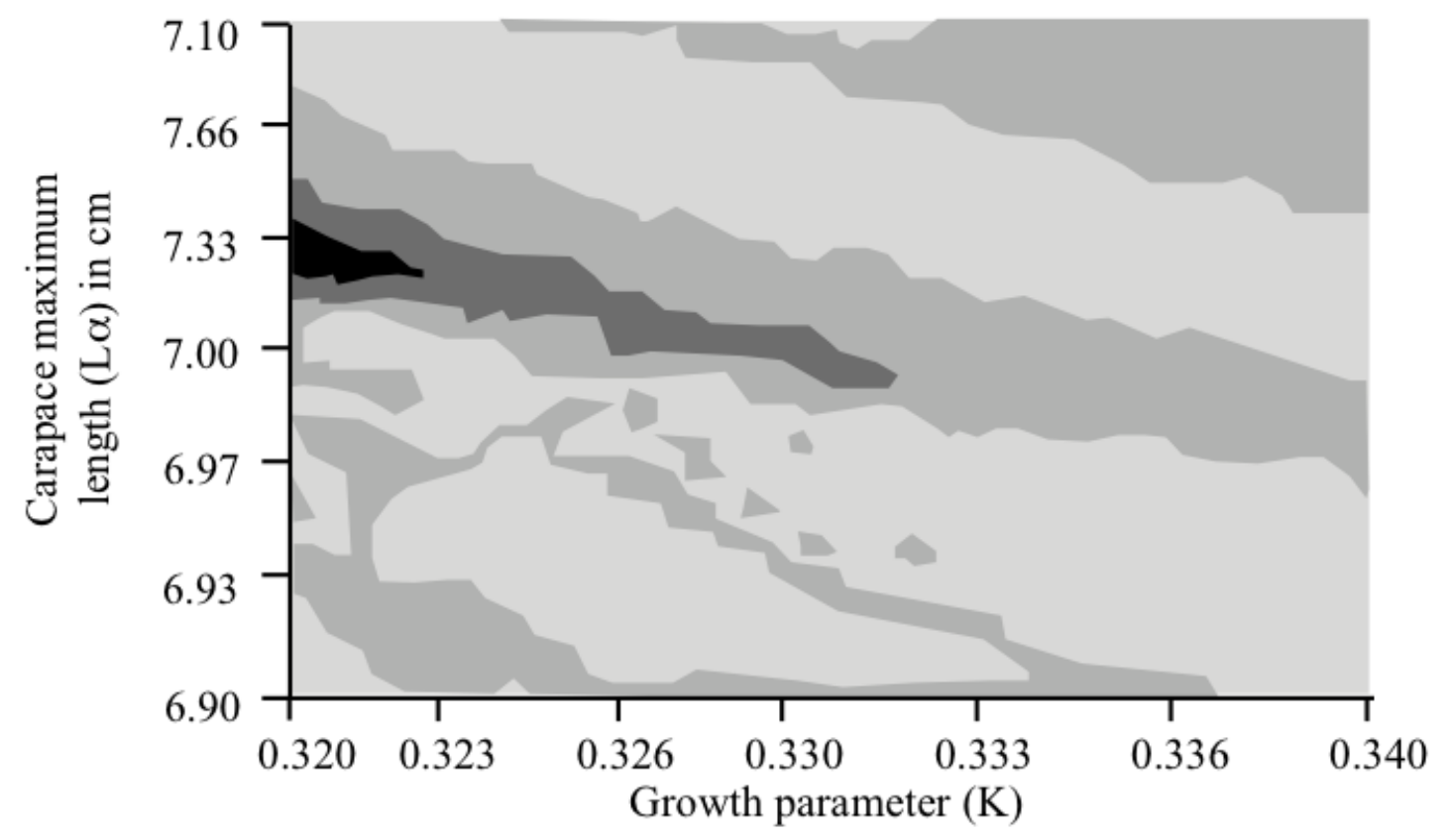

Figure 6. Two dimensional contour plot of $K$ (growth rate) and L $\infty$ (asymptotic length) from von Bertalanffy's seasonal growth model with simulated data for P. clarkii in Doñana National Park temporary freshwater marsh. Light areas represent low values of the score function and the dark areas represent high values. The amplitude of each area shows growth response to the environmental change.

The SLFD model was used to estimate the total mortality rate (Z) (natural mortality+fishing mortality) when applied to the simulated dataset. Changing the minimum size at which crayfish were captured affected the mortality rate, as shown in Figure 7, in which zero represents the boundary between growth and decline of the population. Values above zero indicate that the population is decreasing, while lower values indicate no effect of fishing on the population and that it may continue to grow. Thus, the model predicts that the mortality rate would be highest if the minimum length at first capture was $5.5 \mathrm{~cm} \mathrm{CL}$. If smaller crayfish were caught, the mortality rate would be less and if the minimum length was of $6.0 \mathrm{~cm} \mathrm{CL}$ or more there would be no effect of fishing compared to natural mortality. The optimum target for minimum length at capture is therefore in the range $4-5.5 \mathrm{~cm}$.

The insert in Fig. 7 shows the model for fishing effort in individual months, rather than for the pooled data for four months. This shows that the most effective months for fishing to achieve a high rate of mortality are February and March, i.e. just before a new cohort of crayfish is produced.

This seasonal effect is also shown in the estimates of monthly growth pattern $(\mathrm{K} / \mathrm{Z})$ in Table 3, which compares the parameters for the pooled recorded dataset and the 
simulated dataset. The highest $Z$ values were recorded in January (5.353) and the lowest in April (3.540) at the beginning of the recruitment period (crayfish length (mean \pm Std. error): $2.3 \pm 0.19 \mathrm{~cm} \mathrm{CL}$ ). It is in April when adult crayfish activity declines due to the seasonal decrease in the temporary freshwater marsh water level (crayfish length: $3.66 \pm$ $0.24 \mathrm{~cm} \mathrm{CL}$ ). Growth patterns between recorded and simulated dataset show some differences in the parameters because natural populations show high mortality rates in the small size classes, whereas the simulated population has higher mortality rates at larger size classes.

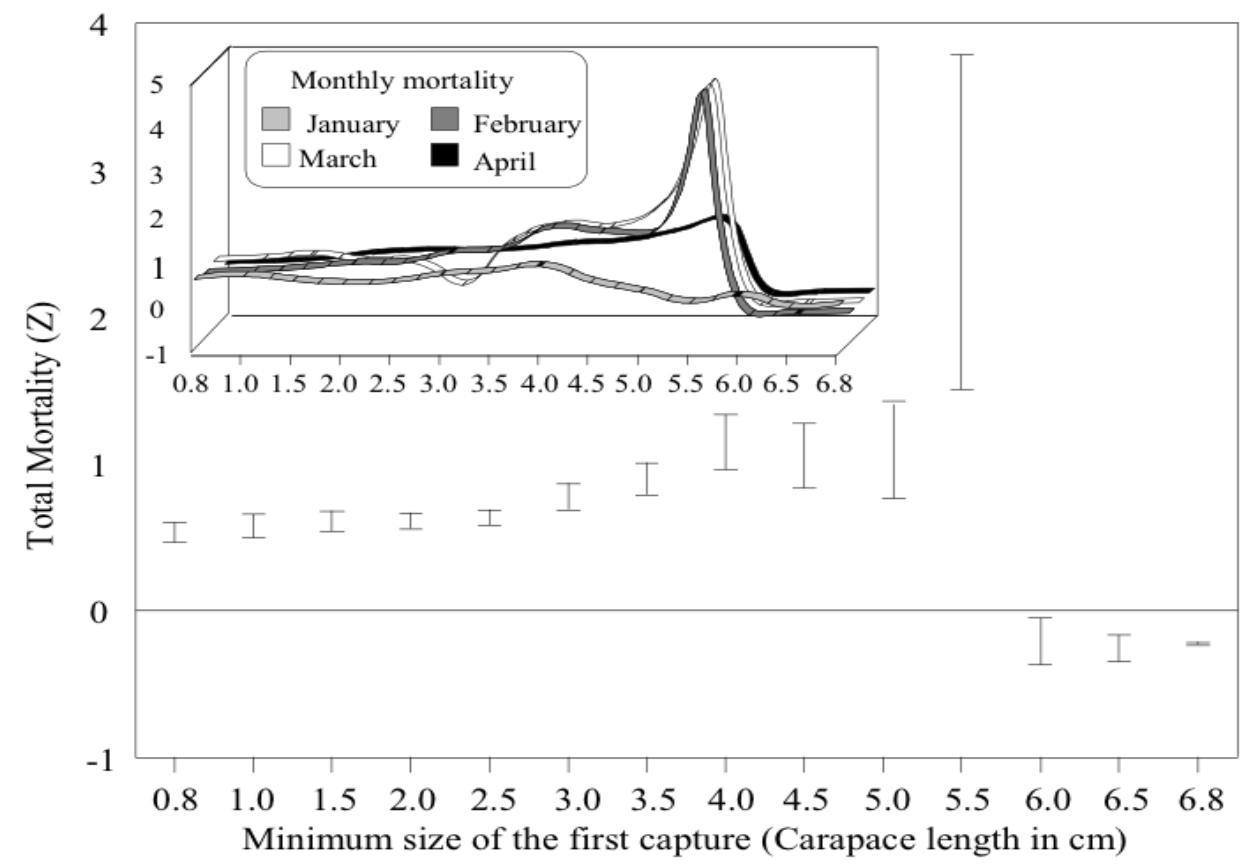

Figure 7. Yearly total mortality rates (natural mortality + fishing mortality) of P. clarkii at different sizes of first capture in Doñana National Park natural temporary freshwater marsh. Vertical lines show the standard error on the mean. Small figure shows monthly total mortality of crayfish.

Converted catch data mortality of P. clarkii, $\operatorname{Ln}(\mathrm{N} / \square \mathrm{T})$ is plotted in Fig. 8. April is the time of maximum mortality due to natural and fishing activity. This total of high mortality rate coincides with a population dominated by large sized individuals $(>5 \mathrm{~cm}$ CL). Simulated dataset showed that maximum total mortality must be on February.

Table 3. Monthly growth pattern estimates (ratio K/Z) of P. clarkii in Doñana National Park natural temporary freshwater marsh with recorded and simulate datasets.

\begin{tabular}{|c|c|c|c|c|c|}
\hline \multirow[b]{2}{*}{ Month } & \multicolumn{4}{|c|}{$\underline{\text { Recorded dataset }}$} & \multirow{2}{*}{$\frac{\text { Simulate data }}{\mathrm{K} / \mathrm{Z}}$} \\
\hline & $L \infty$ & $\mathbf{K}$ & $\mathbf{Z}$ & $\mathbf{K} / \mathbf{Z}$ & \\
\hline \multirow{5}{*}{$\begin{array}{c}\text { January } \\
\text { February } \\
\text { March } \\
\text { April } \\
\text { Mean } \pm \text { Std.error }\end{array}$} & 6.73 & 0.340 & 5.353 & 1.82 & 0.51 \\
\hline & 5.45 & 0.336 & 3.840 & 1.29 & 0.52 \\
\hline & 5.52 & 0.339 & 3.598 & 1.22 & 0.63 \\
\hline & 5.92 & 0.339 & 3.540 & 1.20 & 0.64 \\
\hline & $5.91 \pm 0.17$ & $0.338 \pm 0.084$ & $4.08 \pm 0.740$ & $1.38 \pm 0.084$ & $0.57 \pm 0.019$ \\
\hline
\end{tabular}


By taking into account how certain environmental factors (hydroperiod and water physicochemical mainly), combined with individual growth factors (rate and type of growth) and, the ecology of populations (survival rates, mortality, growth and maximum size growth) determine the final size of the population, it could be established a general model that focuses fisheries to reducing the size of the populations of crayfish in the seasonal freshwater marsh of Doñana.

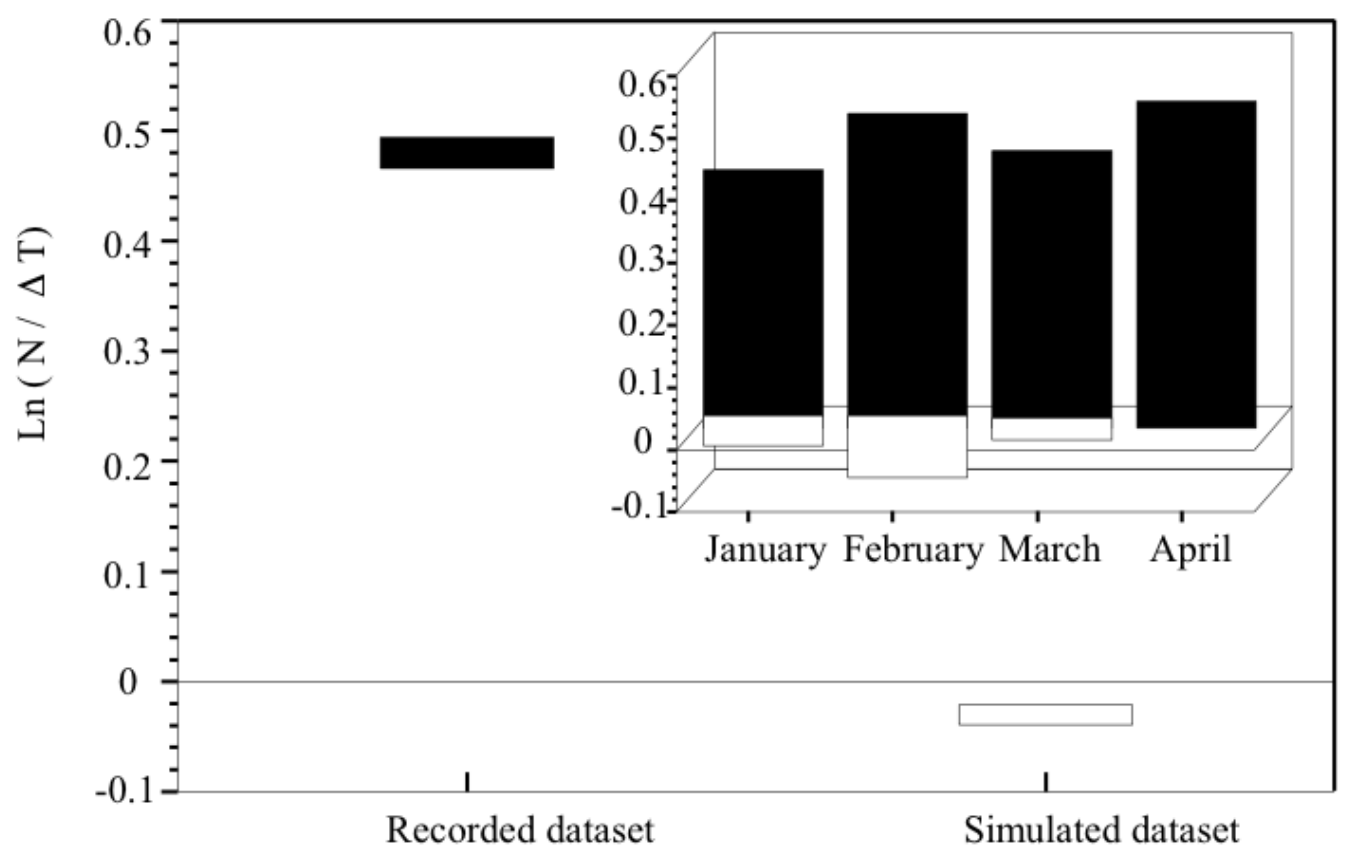

Figure 8. Modeled annual [or seasonal] mortality rate (Z) of P. clarkii in DNP derived from recorded and simulated datasets combined, showing the effect of fishing for different minimum sizes of crayfish on the total mortality rate. Small figure shows monthly converted catch datasets combined.

Proposal of major events that may occur to determine the size classes structure of $P$. clarkii populations in DNP freshwater marsh are showed in Figure 9; for instance, fishing in the two optimal months with the target minimum length at first capture has the potential to reduce the population in more than $70 \%$ compared to its initial size, based on pooled recorded data when hydroperiod is about 4 months.

\section{Discussion}

P. clarkii has invaded Doñana's freshwater marsh for almost 40 years. Since it was first introduced, park managers have been trying to eradicate it, while at the same time, locals have been trying to get economic benefits. The situation seems harmful to the ecosystem, but beneficial to a group of people (Gutiérrez-Yurrita, 2005; Marchi et al., 2011; Martín-López et al., 2011; Maceda-Veiga et al., 2012; Marchi et al., 2012; Homans and Smith 2013). One management option would be to develop a strictly controlled crayfish fishery (Gutiérrez-Yurrita and Martínez, 2002; Gutiérrez-Yurrita, 2011). 
One of the major tasks to establish any ecological fishery plan is to know the population size limits of the crayfish population we are managing, together with the problems of maintaining other ecological values of their ecosystem (Struzynski, 2002; Gutiérrez-Yurrita, 2009; Martín-López et al., 2011; Chucholl, 2013; Homans and Smith 2013). Conservation strategies, especially in protected natural areas, are often confronted with problems originated in the fishing industry. Predicting fishery potential and developing actions plans for a new fishery from a real estimate of crayfish yield is theoretically a sounder option; however, its accuracy must depend on knowledge of the ecology of the crayfish populations under exploitation (Gutiérrez-Yurrita, 2005; McClain et al., 2007; Holdich et al., 2009). The environmental parameters are decisive factors in the growth of individuals and in the recruitment and survival of a population.

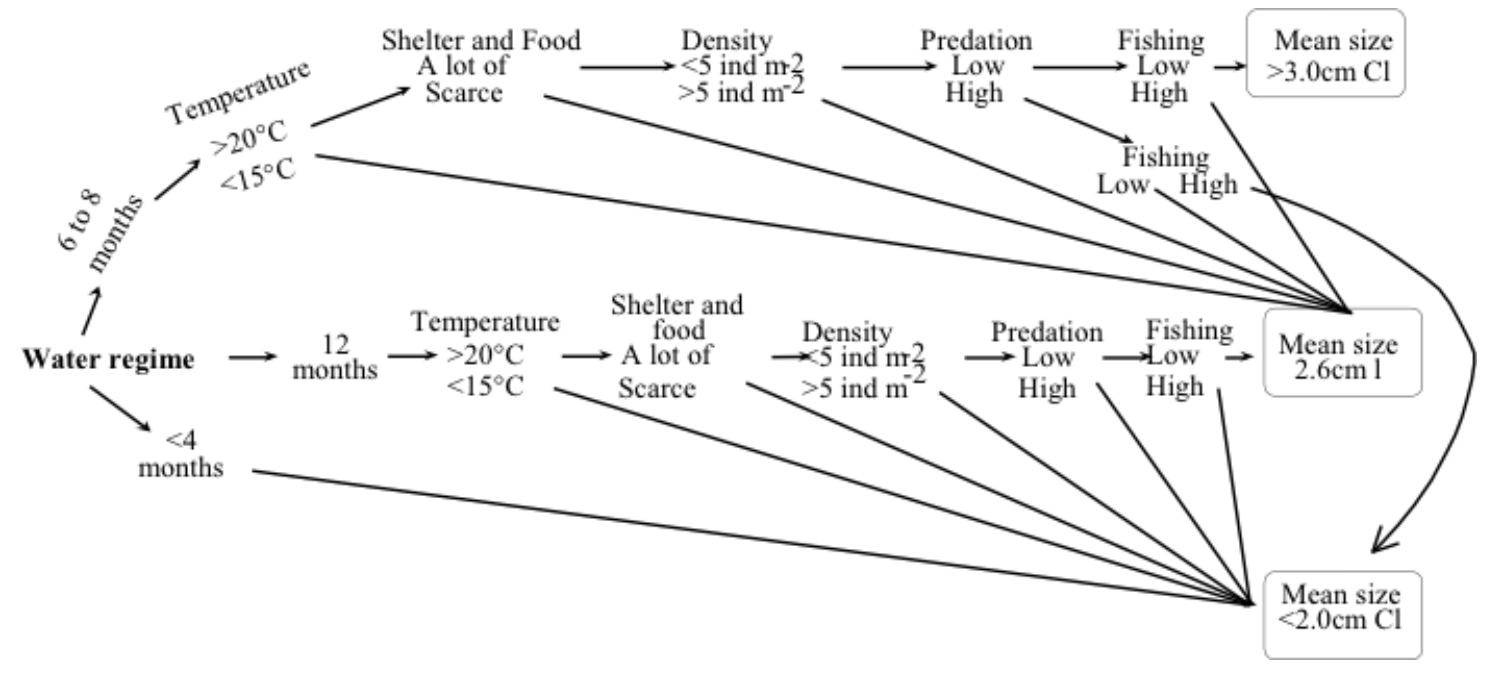

Figure 9. A conceptual ecological model of the factors that may determine the size class structure of P. clarkii populations in Doñana National Park freshwater marsh.

And although we have defined the major environmental factors that modulate the growth of a population, as in this case, the crayfish in Doñana temporary freshwater marsh, there is much uncertainty in the models generated. This leads us to consider that in this very detailed field survey, the management model does not always fit predictions exactly, and it will have variations. Such variations will be higher or lower depending on how the environmental parameters have changed.

To manage $P$. clarkii populations in DNP freshwater marsh we constructed their frequency histograms, estimated their mortality rates and determined their fecundity to create a variable life-table due to the difficulties of estimating the numbers of individuals and age classes of a real cohort in each ecosystem type, and due to their complex reproductive behavior (Cheng et al., 2002; Gutiérrez-Yurrita and Montes, 2004). After this, we can construct theoretical maximum growth curves for each population under exploitation.

Maximum growth curves showed that $P$. clarkii has different growth optimums, differing their growth from one to another just as other characteristics do (sex ratio, proportion of mature individuals, and in a greater extend water quality), and this could affect the yields (Gutiérrez-Yurrita and Martínez, 2002; Colotelo et al., 2013; Nyboer and Chapman, 2013). The fact that the growth curves seem like straight lines, indicate 
that crayfish population growth in these ecosystems from January to April (Fig. 4). Population structure seems like mature population and this structure is almost constant during the whole flooding period. As a consequence of these population characteristics and differences in growth optimums, recruitment of young crayfish also varies between different populations.

Differences may be genetic or the result of the different environments, or usually a mixture of both (Fevolden and Hessen, 1989; Yue et al., 2010; Maceda-Veiga et al., 2012). Gutiérrez-Yurrita and Montes (1998, 1999a, 2001, 2004) found that physiological and phenotypic differentiation can occur in different crayfish populations of $P$. clarkii into the DNP aquatic ecosystems, and that a likely cause for the differentiation, at least as an initial source, is environmental stress (water regime). Abiotic factors controlling crayfish populations in DNP are, besides water regime, mainly the temperature and water quality and oxygen and ammonia content (Bravo et al., 1994; Gutiérrez-Yurrita, 1997; Maceda-Veiga et al., 2012; Marchi et al., 2012). Among the most important biotic factors are food and refuge places availability, crayfish density, predation and fishing (Reynolds and Souty-Grosset, 2012; GutiérrezYurrita and Montes, 2004; Colotelo et al., 2013). This fact helps us to explain why the ecological impact of $P$. clarkii is very different from one to another ecosystem, and hopefully to gain insight concerning the role of $P$. clarkii on the ecosystems.

Previous studies in Doñana's freshwater ecosystems referred that the disordered proliferation of crayfish promotes a large-scale vegetation loss and major changes in food-web structure behaving P. clarkii as a keystone and engineer species (Bravo et al., 1994; Gutiérrez-Yurrita and Montes, 1998; Gutiérrez-Yurrita et al., 1999; GutiérrezYurrita and Montes, 2001; Ilhéu et al., 2007; Marchi et al., 2011). Management measures concerning crayfish populations in DNP freshwater marsh must have as their basic objective the reduction of the pressure that this species exerts on the aquatic macrophyte prairies, when they reach high densities of individuals and the system becomes permanently flooded (Gutiérrez-Yurrita, 1997; Geiger et al., 2005). The control of populations of $P$. clarkii could be developed essentially by two methods: management of the water regime (Momot, 1993; Gutiérrez-Yurrita, 1997; Kerby et al., 2005), and by selective and/or controlled fishing (Westman and Westman, 1992; Momot, 1993; Gutiérrez-Yurrita, 2004). The purpose of both methods consists of reducing the intraspecific competition for shelter and food while adequately maintaining the numerical density and structure of the populations for each management objective (Westman and Westman, 1992; Reynolds and Souty-Grosset, 2012). The control of crayfishing can be used in many ways to manage populations in natural environments. Legal restrictions and controls are also very important in managing these populations and crayfish catching in protected areas such as DNP freshwater marsh (GutiérrezYurrita et al., 1999). Crayfishing can be banned completely, for a specific period or for a certain part of each year. And only imposing minimum size restrictions or favoring one sex over another can target a certain part of the crayfish population.

Our results demonstrated that any DNP management strategies need to contemplate a scheme to control numbers of $P$. clarkii and to develop a good device for crayfishing following the next recommendations:

- The opening of the crayfish-catching season should start in the middle of the freshwater marsh-flooding period, prior to the greatest crayfish reproduction period (January to February), and should end before the beginning of the spring mating season (March to April). 
- Fishing efforts should target on adult individuals (larger than $3.5 \mathrm{~cm} \mathrm{CL}$ ), before of the greatest reproductive peak (March to April), to avoid new recruitments, crowding the populations and promoting the early reproduction of juveniles resulting in stunted populations (Fig. 9).

These dates depend of the rain season and of the other protected species in DNP, because conservationists will try to assure, for instance, the reproduction of migratory waterfowl and the natural macrophyte ecological progression of the freshwater marsh, consisting in the natural changes from a bloom of phytoplankton to a community dominated by helophytes, with some biological or feral states in the middle of this progression such as brief domination of submergent macrophytes followed by a domination of emergent plants. Conservation of these two characteristics of the DNP freshwater marsh helps to preserve the most relevant ecological processes that permit the function of the entire ecosystem: the dynamic equilibrium between the turbid and clear water balances.

This fishing device would reduce some pressure factors dependent of the density of the populations for population growing (Fig. 9), and hence, homogenize population growth by promoting the growth of individuals of slower rates (adults), reaching larger sizes at the reproductive period as shown in Figure 5 simulated data. Ecologically, this is important because the growth phase would be at the end of the flooding period, reducing the environmental impact on macrophytes and the fishermen pressure on riparian vegetation, fostering waterfowl reproduction. In addition, this fishing scheme would get the wise utilization of this resource because fishermen could fish crayfish of commercial sizes in the Doñana's transformed marsh (rice fields) in the periods of natural freshwater marsh desiccation.

It is worth noting that the crayfish fishery strategy in DNP is quite different of other fisheries because our results are based on three short reproductive cycles of $P$. clarkii because of the seasonality of the marsh. These characteristics of the population also justify the divergence in the results we have to compare real data with the simulated data. However, adjusting data fed the model every season, the model results can be improved significantly. These data are hydroperiod, population growth rate and maximum size of individuals. Due to the growth of crustaceans with many mounting periods, it is easy to determine the cohorts and size classes of $P$. clarkii in DNP freshwater marsh every hydrological period, so we can assess differences in growth due to differences in environmental factors, an then, we can adjust the model.

A holistic approach to manage any natural protected area is a new way to understanding that landscape is a multifunctional territory where the binomial forces "man-nature" do have to interact (Gutiérrez-Yurrita, 2009). The holistic paradigm often includes the view that systems somehow work as a whole and that their functioning cannot be fully understood solely in terms of their constituent parts (Oshri, 2008; Gutiérrez-Yurrita et al., 2014). Crayfishing strategies allow us to determine other policies in order to get a holistic management of the DNP. Policies generated by this paradigm concerning social aspects (fishermen and other locals that use to poach to survive or to improve their profits); environmental services (conservation of natural areas can help us improve the already degraded environmental services and stop the deterioration of the ecosystem functions of landscape); and economic issues (an integrative crayfishing program may enable us to diversify production options in the context of conservation biology) could be the reflection of a well-planned management strategy to the park (San Román et al., 2013; Gutiérrez-Yurrita, 2014). 
It is worth noticing that crayfishing into DNP will be done just in order to control crayfish populations in its freshwater marsh. Park rangers should conduct a joint work with the guards from other areas of the river to avoid any instances of introducing new crayfish into the DNP. Linked to this fishing program, a joint a program of environmental awareness not among fishermen, but the entire local population, must developed because fishermen are using an invasive species and should not be unclear about the purpose of the program. Crayfish is an important economic resource in the region; however, the DNP ecological conservation is important as well. Decision makers must understand that confrontation is never beneficial to either party, so the program management of the temporary freshwater marsh in Donana should take into account the participation of the communities living around the park. Allowing controlled trapping within the park's limits to control the population growth of the crayfish, and extend this proposal to fishermen participation to improve it every season, could be a good start in the holistic management of the region (Gutiérrez-Yurrita et al., 2014).

\section{Conclusions}

1. The study of the ecology of red swamp crayfish is of great importance in understanding future events in the population dynamics of this invasive species. These studies are also of the greatest importance in determining the final structure (size classes) and global population dynamics (migratory and reproductive behavior, etc.), which to a certain extent determine the management strategy to be implemented. When there is an excessive increase in the density of juveniles in a population and conditions are stressful, their growth will be deficient; they will develop less and reach maturity without having attained the energy reserves and necessary size to leave offspring in optimal conditions.

2. On the one hand, if the population is also being exploited then it will become a stunted population. In social and economic terms, the fact that individuals of smaller than commercially viable size characterize the exploited population, or one which it is desired to exploit, will cause very important economic repercussions, giving rise to a fall in the price of the individuals of this size, and an increase in those of very large size. On the other hand, knowledge of mortality, growth rates and recruitment strategies of $P$. clarkii as were estimated in this study are of considerable importance to develop new techniques to get sustainable aquaculture practices in this significant protected natural area of Europe.

3. The Holistic perception to manage Donana National Park includes, in an integrated policy, the emergent characteristics of this complex systems, not only the three great themes (economic, social and environmental), but perspectives of how to get benefits from an undesirable situation. Only in this way we can assure conservation policies in an area very crowded by tourists, fishermen, peasants and pilgrims to the biggest religious fest in Spain, the Rocío.

4. Linked to the crayfishing strategy, a program of environmental awareness must be developed in the entire local population, because fishermen are using an invasive species and this should not be the purpose of the program.

Acknowledgements. Authors wish to thank the Estación Biológica de Doñana, CSIC (Sevilla) and the Patronato del Parque Nacional de Doñana for permitting us to develop the field work in Doñana National 
Park. Pedro J. Gutiérrez-Yurrita also thanks the ICI (Spain) for a subvention grant and CONACyT (México) for a financial complement of the former grant that enabled him to complete this research. We also thank Arantxa López, expert biologist, for her invaluable help in the field works.

Change history: The online version of this manuscript was modified on $23^{\text {rd }}$ May 2016. Author names were added to species names Lymnaea peregra and Lymnaea stagnalis.

\section{REFERENCES}

[1] Ackefors, H. (2000): Freshwater crayfish farming technology in the 1990s: a European and global perspective. -Fish and Fisheries 1: 337-359.

[2] Anastácio, P., Parente, V.S., Correia, A.M. (2005): Crayfish effects on seeds and seedlings: identification and quantification of damage. -Freshwater Biology 50:697-704.

[3] Asensio, J.M. (1991): Impacto de la captura del cangrejo rojo sobre otras poblaciones de animales del Brazo del Este. -Junta de Andalucía, Sevilla.

[4] Bertalanffy, L.V. (1934): Untersuchungen über die Gesetzlichkeiten des Wachstums. 1. Allgemeine Grundlagen der Theorie. -Roux'Arch Entwicklungsmech Org 131:613-653.

[5] Bravo, M.Á., Duarte, C., Montes, C. (1994): Environmental factors controlling the life history of Procambarus clarkii (Decapoda, Cambaridae) in a temporary marsh of the Doñana National Park (SW, Spain). -Veha Inter. Verein Limnology 25: 2450-2453.

[6] Carmona, C., Rodríguez-Serna, M., Olvera-Novoa M., Gutiérrez-Yurrita, P. J. (2004): Gonad development, spawning, growth and survival of the crayfish Procambarus llamasi at three different water temperatures. -Aquaculture 232: 305-316.

[7] Cloern, J.E., Nichols F.H. (1978): A von Bertalanffy Growth Model with a Seasonally Varying Coefficient. -J of the Fishery Research Board of Canada 35: 1479-1482.

[8] Colotelo, A.H., Raby, G.D., Hasler, C.T., Haxton, T.J., Smokorowski, K.E., BlouinDemers, G., Cooke, K.E. (2013): Northern pike by catch in an inland commercial hoop net fishery: Effects of water temperature and net tending frequency on injury, physiology, and survival. -Fishery Research, 137:41-49.

[9] Cheng, H.Y.W., Lawrence, C.S., Morrisy, N.M., Bellanguer, J.E. (2002): The statistical correlations and implied causal relationships among physical, chemical, and biological parameters and yabby (Cherax albidus Clark) production in Western Australia farm dams. -Freshwater Crayfish, 13: 67-79.

[10] Chucholl, C. (2013): Invaders for sale: trade and determinants of introduction of ornamental freshwater crayfish. -Biological Invasions 15:125-141.

[11] Correia, A.M., Bandera, N., Anastácio, P. (2005): Predator-prey interactions of Procambarus clarkii with aquatic macroinvertebrates in single and multiple prey systems. -Acta Oecologica 28:337-343.

[12] Crehuet, M., Alcorlo, P., Baltanás, A., Montes, C. (2007): Assessing crayfish trophic ecology: the case of the invasive Procambarus clarkii. In: Gherardi F.(ed.) Biological invaders in inland waters: profiles, distributions and threats. -Invertebrate Ecology 2: 559-576.

[13] Elio-Siesa, M., Manenti, R., Padoa-Schioppa, E., Bernardi F., Ficetola, G.F. (2011): Spatial autocorrelation and the analysis of invasion processes from distribution data: a study with the crayfish Procambarus clarkii. -Biological Invasions 13(9): 2147-2160.

[14] Elvira, B. (1998): Impact of introduced fish on the native freshwater fish fauna of Spain. In: Cowx IG. (ed.) Stocking and introduction of fish. -Fishing news books 1:186-190.

[15] Fevolden, S.E., Hessen, D.O. (1989): Morphological and genetic differences among recently founded populations of noble crayfish (Astacus astacus). -Hereditas 110:149158. 
[16] Geiger, W., Alcorlo, P., Baltanás, A., Montes, C. (2005): Impact of an introduced Crustacean on the trophic webs of Mediterranean wetlands. -Biological Invasions 7:4973.

[17] Gutiérrez-Yurrita, P.J. (1997): El Papel Ecológico Del Cangrejo Rojo (Procambarus clarkii), En El Parque Nacional De Doñana. Una Perspectiva Ecofisiológica y Bioenergética. -PhD Thesis, Universidad Autónoma de Madrid, Spain.

[18] Gutiérrez-Yurrita, P.J. (2004): The use of the crayfish fauna in México: Past, Present... and future?. -Freshwater Crayfish 14: 45-51.

[19] Gutiérrez-Yurrita, P.J. (2005): The problem of introducing alien crayfish: news from México. -Crayfish News 27:12-13.

[20] Gutiérrez-Yurrita, P. J. (2009): ¡A diseñar el futuro! El holismo de la tercera cultura. Instituto Politécnico Nacional-Centro de Estudios Jurídicos y Ambientales. México, D.F.

[21] Gutiérrez-Yurrita, P. J. (2011): How to restore riverbanks in natural ecosystems with many people using ecological services at the same time? -Chemical Engineering and Applications 23:15-20.

[22] Gutiérrez-Yurrita, P. J. (2014): A socio-economical perspective for a holistic management of temporary watersheds in Central Mexico based on a simple mathematical model for decision-makers. -Inter. Jour. Nat. Sci. Res. (in press)

[23] Gutiérrez-Yurrita, P.J., Martínez, J.M. (2002): Analyse ecologique de l'impact ambiant de la population du ecrevisse rouge (Procambarus clarkii), a Tenerife, les Canaries, Espagne, et ses formes de minorizer. -L'Astaciculteur de France 71: 2-12.

[24] Gutiérrez-Yurrita, P.J., Montes, C. (1998): L'écrevisse rouge (Procambarus clarkii) dans le Parc National de Doñana. -L'Astaciculteur de France 55: 2-6.

[25] Gutiérrez-Yurrita, P.J., Montes, C. (1998): Studies of the environmental factors controlling the crayfish Procambarus clarkii activity in the Donana National Park temporary freshwater marsh, SW-Spain. -Comp. Biochem. Physiol 120:713-721.

[26] Gutiérrez-Yurrita, P. J., Montes, C. (1999a): Bioenergetics and phenology of reproduction of the introduced red swamp crayfish Procambarus clarkii in Doñana National Park (Spain), and implications for management. -Freshwater Biology 42: 561574

[27] Gutiérrez-Yurrita, P.J., Montes, C. (1999b): Population dynamics and phenotypic comparisons among six populations of Procambarus clarkii from the Doñana National Park (SW, Spain). -Freshwater Crayfish 12:629-642.

[28] Gutiérrez-Yurrita, P.J., Montes, C. (2001): Bioenergetics of juveniles of red swamp crayfish (Procambarus clarkii). -Comp. Biochem. Physiol. 130:29-38.

[29] Gutiérrez-Yurrita, P.J., Montes, C. (2004): Growth of juveniles of red swamp crayfish (Procambarus clarkii) under controlled conditions. -Freshwater Crayfish 14:144-155.

[30] Gutiérrez-Yurrita, P.J., Ilhéu, M., Montes, C., Bernardo, J.M. (1996): Morphometrics of red swamp crayfish from a temporary marsh (Doñana National Park, SW. Spain) and a temporary stream (Pardiela stream, S. Portugal). -Freshwater Crayfish 11: 384-393.

[31] Gutiérrez-Yurrita, P.J., Green, A., López-Romero, A., Bravo, M.A., Montes, C. (1997): Diseño de un nuevo modelo de trampa para reducir el impacto de la pesca del cangrejo rojo (Procambarus clarkii) sobre la población de vertebrados en las marismas del Guadalquivir. -Doñana Acta Vertebrata 24: 51-66.

[32] Gutiérrez-Yurrita, P.J., Sancho, G., Bravo, M.A., Baltanás, A., Montes, C. (1998): Natural diet of the red swamp crayfish Procambarus clarkii in the Doñana National Park freshwater marsh (SW, Spain). -Jour. of Crust. Biol. 8:120-127.

[33] Gutiérrez-Yurrita, P.J., Martínez, J.M., Ilhéu, M., Bravo, M.A., Bernardo J.M., Montes, C. (1999): The status of crayfish populations in Spain and Portugal. In: Gherardi F, Holdich DM (eds). Crayfish in Europe as alien species: how to make the best of a bad situation?. -Crustacean issues. Balkema, Rotterdam/Brookfield.UK,pp 161-192. 
[34] Gutierrez-Yurrita, P. J., Ortega, A., Álvarez, A., García, L., Rebollar, M. (2014): The holistic management of the landscape of ethnic communities will reduce climate change and promote its sustainability. -Inter. Jour. of Environ. Sci. and Develop. 5(3): 317-323

[35] Holden, S., Kirkwood, G., Bravington, M. (1995): Length Frequency Distribution Analysis (LFDA). -Fish Management Science Programme of the Overseas Development Administration. MRAG. London.

[36] Holdich, D.M., Reynolds, J.D., Souty-Grosset, C., Sibley, P.J. (2009): A review of the ever increasing threat to European crayfish from non-indigenous crayfish species. KMAE 11:394-395.

[37] Homans, F.R., Smith, D.J. (2013): Evaluating management options for aquatic invasive species: concepts and methods. -Biological Invasions 15:7-16.

[38] Ilhéu, M. \& Bernardo, J.M. (1995) Trophic ecology of red swamp crayfish Procambarus clarkii (Girard). Preferences and digestibility of plant foods. -Freshwater Crayfish 10: 221-229.

[39] Ilhéu, M., Bernardo, J.M. Fernandes, S. (2007): Predation of invasive crayfish on aquatic vertebrates: the effect of Procambarus clarkii on fish assemblages in Mediterranean temporary streams. In: Gherardi F. (ed.) Biological invaders in inland waters: profiles, distributions and threats. -Invertebrate Ecology 29:543-558.

[40] Kerby, J.L., Riley, S., Kats, L.B., Wilson, P. (2005): Barriers and flow as limiting factors in the spread of an invasive crayfish (Procambarus clarkii) in southern California streams. -Biological Conservation 126: 402-409.

[41] Maceda-Veiga, A., De Sostoa, A., Sánchez-Espada, S. (2012): Factors affecting the establishment of the invasive crayfish Procambarus clarkii (Crustacea, Decapoda) in the Mediterranean rivers of the northeastern Iberian Peninsula. -Hydrobiologia. http://link.springer.com/article/10.1007\%2Fs10750-012-1335-2. Accessed 30 October, 2012.

[42] Martín-López, B., García-Llorente, M. , Palomo, I., Montes, C. (2011): The conservation against development paradigm in protected areas: Valuation of ecosystem services in the Doñana social-ecological system (southwestern Spain). -Ecological Economics 70: 14811491.

[43] Marchi, M, Jørgensen, S.E., Bécares, E., Fernández-Aláez, C. , Rodríguez, C. , Fernández-Aláez, M., Pulselli, F.M., Marchettini, N., Bastianoni, S. (2012): Effects of eutrophication and exotic crayfish on health status of two Spanish lakes: a joint application of ecological indicators. -Ecological Indicators 20: 92-100.

[44] Marchi, M., Jørgensen, S.E., Bécares, E., Corsi, I., Marchettini, N., Bastianoni, S. (2011): Dynamic model of Lake Chozas (León, NW Spain)—Decrease in eco-exergy from clear to turbid phase due to introduction of exotic crayfish. -Ecological Modeling 222: 30023010 .

[45] Matsuzaki, S.S., Usio, N., Takamura, N., Washitani, I. (2009): Contrasting impacts of invasive engineers on freshwater ecosystems: an experiment and meta-analysis. Oecologia 158: 673-685.

[46] McClain, W.R., Romaire, R.P., Lutz, Ch., Shirley, M.G. (2007): Crawfish production manual. -Publication \#2637. Louisiana State University Agricultural Center. Baton Rouge, Louisiana, USA.

[47] Momot, W.T., Romaire, R.P. (1983): Use of a seine to detect stunted crawfish populations in ponds, a preliminary report. -Jour. World Mar. Soc. 12:384-390.

[48] Momot, W.T. (1993): The role of exploitation in altering the processes regulating crayfish populations. -Freshwater Crayfish 9:101-117.

[49] Montes, C., Bravo, M.A., Baltanás, A., Gutiérrez-Yurrita, P.J. (1993): El papel ecológico del cangrejo rojo de las marismas en el parque Nacional de Doñana. -Informe técnico. Junta de Andalucía, Universidad Autónoma de Madrid. 
[50] Montes, C., Borja, F., Bravo, M.A., Moreira, J.M. (1998): Doñana. Una aproximación ecosistémica. -Reconocimiento Biofísico de Espacios Naturales. Consejería de Medio Ambiente, Junta de Andalucía. Sevilla.

[51] Montesinos, A., Santoul, F., Green, A.J. (2008): The Diet Of The Night Heron And Purple Heron In The Guadalquivir Marshes. -Ardeola 55(2): 161-167.

[52] Nyboer, E.A., Chapman, L.J. (2013): Movement and home range of introduced Nile perch (Lates niloticus) in Lake Nabugabo, Uganda: Implications for ecological divergence and fisheries management. -Fisheries research 137:18-29.

[53] Ott, R.L. (1993): An introduction to statistical methods and data analysis. -Duxbury Press. New York.

[54] Oshry, B. (2008): Seeing Systems: Unlocking the Mysteries of Organizational Life. Berrett-Koehler Pub. UK.

[55] Pauly, D, Morgan, G.R. (1987): Length based methods in fisheries research. -ICLARM. Manila, Philippines and KISRI, Safat, Kuwait.

[56] Pitcher, T.J., Hart, H.P.B. (1982): Fisheries ecology. -The Avi Publishing Co. Connecticut.

[57] Pöckl, M. (2002): Draft program for the conservation of native crayfish species in Austria. -Freshwater Crayfish 13:221-232.

[58] Reynolds, J.D., Souty-Grosset, C. (2012): Management of Freshwater Biodiversity: Crayfish as Bioindicators. -Cambridge University Press, U.K.

[59] Rodríguez, C.F., Becares, E., Fernández-Alavés, M., Fernández-Álvarez, C. (2005): Loss of diversity and degradation of wetlands as a result of introducing exotic crayfish. Biological Invasions 7:75-85.

[60] Romaire, R.P., McClain, W.R., Shirley, M.G., Lutz, Ch. (2005): Crawfish aquaculture: marketing. -SRAC Publication No. 2402. Southern Regional Aquaculture Center, Mississippi, USA.

[61] San Román, J., Marín-García, L., Muñoz, P., López, M.A., Gutiérrez-Yurrita, P.J. (2013): Ecological considerations for the management of a protected area with a strong urban pressure: the case of Lake Texcoco, México. -Inter. Jour. of Ecology and Environ. Sciences 39(1):26-36.

[62] Scheffer, M., Hosper, S.H., Meijer, M-L., Moss, B., Jeppesen, E. (1993): Alternative equilibria in shallow lakes. -TREE 8: 275-279.

[63] Seafood (2012): http://www.seafood-today.com/noticia.php?art_clave=865 page visited December 8th, 2012.

[64] Struzynski, W. (2002) The program for restocking noble crayfish (Astacus astacus L.) in middle east Poland. -Freshwater Crayfish 13: 240-244.

[65] Wang, Y.G. \& Thomas, M.R. (1995) Accounting for individual variability in the von Bertalanffy growth model. -Can. Jour. Fish. Aquat. Sci. 52: 1368-1375.

[66] Westman, K., Westman, P. (1992): Present status of crayfish management in Europe. Finnland Fisheries Research 14: 1-22.

[67] Wetherall, J.A., Polovina, J.J., Ralston, S. (1987): Estimating growth and mortality in steady-state fish stocks from length-frequency data. -ICLARM 13:53-74.

[68] Yue, G.H., Li, J., Bai, Z., Wang, C.M., Feng, F. (2010): Genetic diversity and population structure of the invasive alien red swamp crayfish. -Biological invasions 12: 2697-2706. 